\title{
A COEXISTÊNCIA DO PENSAMENTO CARTESIANO E SISTÊMICO: AS LIMITAÇÕES TERRITORIAIS ENFRENTADAS PELO PAA E PNAE EM PELOTAS/RS
}

\section{The coexistence of the cartesian and the sytemic thinking: the territorial limitations faced by the PAA and the PNAE in Pelotas/RS}

\author{
Maiara Tavares Sodré \\ Universidade Federal de Pelotas, Pelotas, Rio Grande do Sul, Brasil. \\ maiara.sodre@hotmail.com \\ Giancarla Salamoni \\ Universidade Federal de Pelotas, Pelotas, Rio Grande do Sul, Brasil. \\ gi.salamoni@yahoo.com.br
}

Artigo recebido em 17/05/2016 e aceito para publicação em 15/12/2016

RESUMO: O presente trabalho aborda as limitações territoriais enfrentadas pelo Programa de Aquisição de Alimentos (PAA) e pelo Programa Nacional de Alimentação Escolar (PNAE) em seu processo de operacionalização no município de Pelotas a partir da visão de três grupos de entrevistados: agricultores fornecedores, instituições mediadoras e entidades executoras. Adota-se como método a abordagem sistêmica, operacionalizada através de trabalho de campo para realização de entrevistas, estas exploradas por meio de análise de conteúdo. De modo geral, verifica-se uma tendência de cada um dos três grupos pesquisados em associar, majoritariamente, as limitações territoriais dos programas à atuação dos outros dois grupos envolvidos, minimizando os problemas ou dificuldades decorrentes da sua própria ação. Enquanto as entidades executoras associam as limitações territoriais essencialmente aos fornecedores, estes imputam as limitações principalmente às executoras. Os mediadores preferem, por sua vez, associar parte dos problemas enfrentados à alçada das executoras e outra parte aos fornecedores. Colige-se que essa tendência decorre de uma visão de mundo cartesiana e fracionada, que enxerga apenas as partes e, por isso, não pode compreender a complexidade da realidade e do contexto que cerca e condiciona a ação de cada indivíduo.

Palavras-chave: Abordagem sistêmica; Trabalho de campo; Políticas públicas; Agricultura familiar. Território.

\begin{abstract}
The present paper approches the territorial limitations faced by the Food Acquisition Program (PAA) and by the National School Feeding Programme (PNAE) in its process of operationalisation in Pelotas from the perspective of three interviewed groups: farmers suppliers, mediating institutions and implementing entities. It adopts as its method a systemic approach, operationalized through fieldwork to conduct the interviews, which were exploited by an analysis of the content. In general it shows a tendency in each one of the three groups, that were investigated, in associate, mainly, the territorial limitations of the programs performance in the other two groups involved, minimizing the problems or difficulties recuring from its own action. While the implementing entities associate the territorial limitations essentially to suppliers, these attributes with limitations mainly from the executors. On the other hand, the intermediaries prefer to associate a share of the problems facing the purview of executors and another part to suppliers. We may infer that this trend elapses from a cartesian and fractioned vison of the world, that only sees the parts, and therefore, can not understand the complexity of reality and context that surronds and conditions the action of each individual.
\end{abstract}

Keywords: Systemic approach; Fieldwork. Public policies; Family farming; Territory. 


\section{INTRODUÇÃO}

Políticas públicas são instrumentos de intervenção estatal voltados para mitigar problemas ou contradições presentes nas diversas esferas da administração governamental, como educação, saúde, economia, emprego, renda ou segurança. De modo geral, a formulação e implementação de políticas públicas guarda estreita relação com as pressões e reivindicações exercidas pela sociedade. No entanto, no caso da agricultura, a elaboração de políticas públicas responde não somente às demandas do rural, mas encontra uma motivação especial na dinâmica particular da atividade agrícola, isto é, no caráter descontínuo da produção de alimentos e matérias-primas e nas deformações de mercado geradas por essa especificidade.

O presente trabalho objetiva abordar as limitações territoriais enfrentadas pelo Programa de Aquisição de Alimentos (PAA) e pelo Programa Nacional de Alimentação Escolar (PNAE), em seu processo de operacionalização no município de Pelotas, a partir da visão de agricultores fornecedores, instituições mediadoras e entidades executoras. Para isso, utiliza-se de trabalho de campo para realização de entrevistas com os referidos grupos de informantes e, posteriormente, submetidas aos procedimentos de análise de conteúdo. Esse instrumental metodológico é operado com base na orientação de método da abordagem sistêmica. Por meio desta são estabelecidos os pontos de consonância entre as perspectivas de cada grupo de informantes e explicita-se uma tendência à segmentação e disposição cartesiana na forma como os entrevistados aferem a atuação do seu próprio grupo e dos demais envolvidos no funcionamento dos programas em Pelotas.

É necessário ressaltar que o presente artigo constitui capítulo da dissertação de mestrado da autora, na qual não somente as limitações territoriais enfrentadas por PAA e PNAE foram foco de análise da pesquisa, mas também as potencialidades territoriais descortinadas no município ao desenvolvimento desses programas. A abordagem exclusiva das limitações neste trabalho não objetiva o apontamento de uma visão depreciativa do território, tratando-o como um entrave ao processo de operacionalização das políticas públicas, $\mathrm{o}$ que, como haverá ocasião de demostrar, reflete justamente a antítese da perspectiva de enfoque do conceito de território defendida. A opção por tratar nesta ocasião apenas das limitações tem como intuito, antes, a melhor explicitação das diretrizes norteadoras das linhas de argumentação dos entrevistados, de modo a enfatizar a orientação cartesiana de seu olhar sobre os problemas territorialmente enfrentados pelos programas.

\section{PAA E PNAE EM PELOTAS: O ENFOQUE DA ANÁLISE}

O Programa de Aquisição de Alimentos foi instituído em 2003, com o intuito de assegurar o provimento de alimentos em quantidade, qualidade $\mathrm{e}$ constância adequadas para as necessidades de grupos em condição de insegurança alimentar e nutricional, proporcionando, destarte, a inclusão social dessas populações, além de estimular o fortalecimento da agricultura. Operacionalmente, o PAA estrutura-se em diferentes modalidades voltadas, sobretudo, para a compra pública de produtos (tanto in natura quanto processados) da agricultura familiar a preços garantidos, contemplando preferencialmente os agricultores menos capitalizados. Os alimentos adquiridos aprovisionam abrigos, hospitais, creches, instituições públicas, restaurantes populares e são doados para populações em situação de insegurança alimentar, cadastradas em programas de assistência estatal ou beneficente, podendo ainda ser utilizados para a formação de estoques públicos.

A experiência positiva do PAA transcendeu os limites do programa, incentivando uma mudança significativa para a inserção da agricultura familiar no Programa Nacional de Alimentação Escolar (PNAE). O que ocorreu em 2009, quando se estabelece a imposição legal de que pelo menos $30 \%$ dos recursos expedidos pelo governo federal, por meio do Fundo Nacional de Desenvolvimento da Educação (FNDE), para aquisição de alimentação escolar sejam despendidos pelos estados e municípios na aquisição de alimentos advindos da agricultura familiar. Ademais, escusam-se os alimentos da agricultura familiar, adquiridos por meio de chamada pública, da obrigatoriedade de passarem por processo licitatório, eliminando a burocracia desses procedimentos que limitavam o acesso dos agricultores familiares ao programa (TRICHES; SCHNEIDER, 2010). 
Como é possível perceber, existem diferentes âmbitos de operação do PNAE e do PAA, como também diferentes direcionamentos e instâncias públicas envolvidas nas suas execuções. Neste trabalho analisa-se a única modalidade de PAA vigente em Pelotas atualmente, a de Compra Institucional para o Restaurante Escola (RE) da Universidade Federal de Pelotas (UFPel). Essa modalidade, operada pela UFPel desde setembro de 2014, permite que estados, municípios e instituições federais (como restaurantes universitários, creches, hospitais, presídios e quartéis) adquiram produtos da agricultura familiar sem a necessidade de realização de processo licitatório, através de chamadas públicas. Cada família de agricultores pode comercializar até vinte mil reais por ano por meio do programa, sem prejuízo de seu acesso a outras modalidades de PAA ou ao PNAE. Quanto a este, o estudo focaliza tanto a sua execução estadual quanto municipal em Pelotas.

\section{O DELINEAMENTO DO MÉTODO: DO PEN- SAMENTO CARTESIANO À ABORDAGEM SISTÊMICA}

A forma como os seres humanos compreendem e expressam a realidade que os cerca é variável no tempo, sendo representante e também corolário de uma visão de mundo, de uma determinada perspectiva por meio da qual os processos, fatos, fenômenos e pessoas são percebidos e estudados. Essa perspectiva estabelece regramentos, ideais, valores, ela determina o viés por meio do qual o mundo será focalizado até o momento em que suas lentes já não abarcarem mais a amplitude e a complexidade do real, nesse momento, então, é preciso que ela seja substituída por um novo entendimento. Convencionou-se chamar de paradigma essa visão de mundo e de quebra de paradigma o momento em que o modelo vigente é suplantado por outro de maior escopo e em maior acordo com a realidade (KUHN, 1998).

Desde o final do século XVI e início do XVII o paradigma cartesiano ou mecanicista tem se mostrado hegemônico. Trata-se de uma abordagem inicialmente alicerçada nas descobertas de Copérnico, Galileu e Newton, as quais promoveram profundas mudanças na Astronomia e na Física, reconstruindo as bases dessas ciências e ampliando de forma exponencial o conhecimento humano sobre o mundo. O impacto dessas mudanças sobre as estruturas do conhecimento pode ser explicitado pela forma como esse período é comumente referido: Idade da Revolução Científica. O método originado dessa concepção de mundo ficou conhecido como analítico e se baseou no pensamento de Descartes. Tal método preconiza o uso de linguagem matemática e da analogia que equipara o mundo a uma máquina, cujo estudo deve se dar a partir de seus segmentos e mecanismos mais embrionários e de forma compartimentada (CAPRA, 1982).

A visão de mundo mecanicista extrapola os limites da ciência e perfaz a operacionalidade lógica do pensamento ocidental, manifestando-se na forma segmentada como os seres humanos estruturam sua interpretação da realidade e organizam os aspectos materiais e imateriais que permeiam seu cotidiano. Não obstante, é prudente lembrar que a abordagem cartesiana não atuou somente no seccionamento do pensamento dos seres humanos, impedindo sua visão de conjunto; essa mesma perspectiva também conduziu a humanidade a descobertas científicas que permitiram avanços tecnológicos de uma magnitude ainda hoje difícil de aquilatar. Não há razão para desconsiderar ou minimizar as contribuições à ciência e à sociedade do pensamento cartesiano.

Da mesma forma, também não há motivos para negligenciar o fato de que a abordagem mecanicista promoveu uma fragmentação do conhecimento que insulou mesmo os campos do saber mais próximos. Além de estimular a valorização de uma lógica tecnicista e economicista de produção do conhecimento, insuficiente para gerar uma distribuição equitativa do progresso técnico-científico e dos ganhos econômicos gerados. Foi também essa mesma lógica produtivista patrocinada pelo pensamento cartesiano que acabou por ensejar um grau de exploração da natureza visivelmente insustentável em longo prazo. Afora a consideração desses reflexos extra-científicos do paradigma cartesiano, o método analítico enfrenta ainda os problemas inerentes a sua própria estrutura lógica, como aponta Bachelard (1978):

O método cartesiano é redutivo, não é indutivo. Tal redução falseia a análise e entrava o desenvolvimento extensivo do pensamento objetivo. Ora, não há pensamento objetivo, sem 
objetivação, sem essa extensão. [...] o método cartesiano que consegue explicar tão bem o Mundo, não chega a complicar a experiência, $o$ que é a verdadeira função da pesquisa objetiva (BACHELARD, 1978, p. 159, grifos do autor).

A partir da compreensão dessas limitações, uma quebra de paradigma começa a se delinear de forma mais contundente no começo da segunda metade do século XX, com a publicação dos estudos de Ludwig Von Bertalanffy sobre a Teoria Geral dos Sistemas (TGS). A perspectiva sistêmica, defendida pelo autor, pauta-se em um método que propõe o estudo da totalidade do fenômeno pesquisado, ultrapassando a sua mera segmentação mecânica em partes, as quais sozinhas são insuficientes para a compreensão aprofundada do objeto em questão, não fornecendo mais do que quadros pontuais da realidade. Bertalanffy (1975) defende a totalidade do fato estudado como o objeto por excelência da abordagem sistêmica. Isto é, a dinâmica de um sistema só pode mostrar-se tangível às estruturas cognitivas humanas se houver uma preocupação com a organização desse sistema, com a forma como suas partes se inter-relacionam, articulando-se para a conformação do todo que compõem.

Desse modo, um sistema pode ser conceituado como um agrupamento instável de elementos, partes e processos interagindo em mutualidade. Quando analisado na sua totalidade, esse sistema apresenta propriedades emergentes, não passíveis de identificação por um olhar que particulariza determinados componentes, pois essas propriedades insurgem da interação dinâmica somente perceptível em uma visão que comtemple o todo. Isso significa que, para Bertalanffy (1975), a proposta do método analítico de reconstituir o todo a partir do estudo pormenorizado de suas partes jamais poderia atingir seus objetivos, pois sua premissa essencial não era válida, de modo inverso, é do estudo do todo que se pode atingir as partes e não o contrário.

Nesse sentido, a proposta de abordagem sistêmica aqui aplicada contempla a crítica realizada por Morin (1980) à TGS, tal como ela foi esboçada inicialmente em Bertalanffy (1975). Para Morin (1980) uma interpretação equivocada da TGS pode promover um reducionismo às avessas. Isso porque a fixação no todo pode levar a um desprezo sistemático das partes, obliterando o fato de que todas as propriedades destas não se expressam integramente no todo. Uma vez que a unidade do todo e a sua manutenção enquanto totalidade exigem a supressão de propriedades das partes que são anuladas em favor da identidade do sistema. $\mathrm{O}$ que significa dizer que a existência das partes enquanto componentes do sistema lhes tolhe um grande potencial de possibilidades não efetivadas em razão da existência de imposições originárias do todo, mas também de imposições exercidas das partes sobre as partes, a partir dos laços de interdependência estabelecidos entre elas.

É prudente recordar que a constituição do sistema enquanto totalidade não implica, evidentemente, em um empobrecimento da realidade, uma vez que o todo também comporta propriedades emergentes que não poderiam ser verificadas na individualidade das partes. Mais que isso, a presença das partes no todo acaba por conferir a elas propriedades individuais que elas não possuiriam se fossem analisadas isoladamente. Dessa forma, existe uma relação de perdas e ganhos na constituição do sistema, mas essa relação só pode ser adequadamente identificada se as partes forem focalizadas enquanto elementos do todo, mas também separadamente, na sua singularidade.

Implicitamente, a ideia de que o todo é maior do que o somatório de suas partes indica também como ocorre a organização dos sistemas, os quais comportam sempre sistemas de menor amplitude e complexidade e são abarcados por outros sistemas mais abrangentes e com maior diversidade de conexões entre si, conformando, assim, uma organização hierárquica. Essa organização, contudo, não apresenta uma estabilidade irreversível, podendo ser alterada de acordo com a dinâmica das relações associativas ocorridas nos sistemas. O processo que leva à formatação dessa ordem hierárquica e a sua configuração são abordados por Naveh (2000), referindo-se aos estudos sobre a paisagem o autor entende que:

In our case, such a revolution was initiated by a major paradigm shift from parts to wholes, and from entirely reductionistic and mechanistic approaches to more holistic and organismic ones. It leads to the turning away from breaking down, analyzing and fragmenting wholes into smaller and smaller particles 
towards new trends for integration, synthesis, and complementary. It means the need to replace the reliance on exclusively linear and deterministic processes by non-linear, cybernetic and chaotic processes, based on systems thinking of complexity, networks and hierarchic order (NAVEH, 2000, p. 29-30).

Cabe brevemente lembrar o que enfatiza reiteradas vezes Bertalanffy (1975), a proposta da abordagem sistêmica, em essência, é uma ampliação do campo de visão delimitado pelo método analítico. Sob muitos aspectos, esse método conferiu a determinados grupos (preferencialmente homens, brancos e europeus) um status diferenciado, adjudicando autoritariamente a eles o direcionamento sobre os rumos do progresso científico. A proposta da abordagem sistêmica é a de que a orientação da ciência deve se dar a partir das demandas emanadas de toda a sociedade (e não de parte dela). Tendo muito presente o reconhecimento de que qualquer concepção teórica (inclusive a sistêmica) comporta falhas e limitações, sua validade devendo sempre ser condicionada à observância da realidade.

A abordagem sistêmica é apropriada pela Geografia Agrária, conforme Mazoyer e Roudart (2010) no decorrer da segunda metade do século XX. Segundo os autores, a emergência do conceito de sistemas agrários é uma tentativa de representar teoricamente a agricultura como o produto das relações territorialmente entabuladas em um momento histórico específico, considerando as relações estabelecidas no interior desse território, bem como a forma como a população se relaciona com o exterior. A Teoria dos Sistemas Agrários pode ser empregada com fins exclusivamente acadêmicos ou com intuito de constituir um corpo coeso de conhecimentos capaz de embasar a formulação de políticas públicas voltadas para o desenvolvimento rural (SILVA NETO; BASSO, 2005). Em ambos os casos, porém especialmente no último, é importante que os grupos sociais que compõem um sistema agrário sejam consultados e convidados a compartilhar seus conhecimentos não apenas durante a pesquisa, mas também no momento de desenvolver os projetos entendidos como mais apropriados para o contexto.

Por essa razão, para que fosse possível refletir neste estudo o conteúdo dos problemas, necessidades e aspirações dos grupos entrevistados, entendeu-se como fundamental a utilização do trabalho de campo para realização de entrevistas com os grupos envolvidos na operacionalização dos programas investigados no município de Pelotas. Assim, na seção seguinte contextualizam-se os resultados obtidos por meio do trabalho de campo, mas também enfatiza-se a necessidade de reflexões teóricas mais profundas acerca do emprego desse instrumento pela ciência geográfica. Antes disso, porém, é preciso realizar alguns esclarecimentos acerca das opções teórico-metodológicas que pautam este estudo.

Primeiro, é necessário esclarecer a definição de território a que o estudo se alinha. Nesta pesquisa o conceito foi utilizado em consonância com a vertente que o valoriza pelo seu hibridismo (SANTOS, 2005) e multiplicidade (SOUZA, 2009). Defende-se esse caminho como a possibilidade com maior potencial de aprofundamento teórico e de clareza na representação da realidade, além de propiciar as bases para uma perspectiva multidimensional de desenvolvimento rural, objetivo último da formulação de políticas públicas. Assim, o território será considerado nas suas dimensões material e imaterial, abarcando processos de caráter político, econômico e simbólico-cultural.

Entende-se que essa perspectiva de entendimento do conceito é compatível com a visão sistêmica ora aplicada, pois o território, assim entendido, é capaz de estabelecer conexões entre diferentes aspectos da realidade sem negligenciar o peso diferenciado que cada um desses aspectos pode adquirir de acordo com a conjuntura estudada. Como será demostrado ao debaterem-se as limitações territoriais de PAA e PNAE. Esse entendimento, porém, não se elude da responsabilidade de realização de análises mais dirigidas a aspectos específicos do contexto empírico focalizado, tarefa indispensável quando se pretende analisar como o caráter específico de algumas dinâmicas acaba por condicionar sob todos os ângulos a organização dos territórios.

Uma segunda questão merece esclarecimentos preliminares: o roteiro de entrevistas aplicado. Para garantir a primazia dos grupos entrevistados optou-se pela aplicação de entrevistas por pautas (GIL, 1987). Essa modalidade aproxima-se da entrevista semiestruturada, mas caracteriza-se por uma maior flexibilidade. Seu roteiro permite a demarcação de pontos importantes a serem postos para a apreciação 
do entrevistado e garante que este mantenha observância à temática da entrevista, ao mesmo tempo em que busca limitar a intervenção do pesquisador apenas à garantia do cumprimento desses princípios, prezando pelo protagonismo do informante.

Assim, foram entrevistados sujeitos compreendidos como "elementos-chave" para a pesquisa, originários de três grupos: fornecedores - agricultores familiares beneficiários dos programas afiliados a três cooperativas de agricultores familiares de Pelotas: Cooperativa dos Apicultores e Fruticultores da Zona Sul (CAFSUL), Cooperativa dos Produtores Agrícolas do Monte Bonito (COOPAMB) e Cooperativa Sul Ecológica de Agricultores Familiares Ltda.; mediadores - técnicos da Associação Riograndense de Empreendimentos de Assistência Técnica e Extensão Rural (EMATER/RS), do Centro de Apoio ao Pequeno Agricultor (CAPA) e da Secretaria Municipal de Desenvolvimento Rural (SMDR), que gerenciam a implementação e a operacionalidade das políticas públicas para agricultura familiar no município; e entidades executoras - representantes da Secretaria Municipal

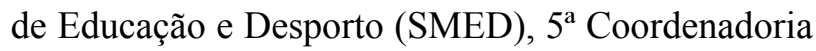
Regional de Educação da Secretaria Estadual de Educação (5 ${ }^{\text {a }}$ CRE-SEDUC), Restaurante Escola e Fundação de Apoio Universitário (FAU) da UFPel. Totalizando um número de dezessete entrevistas.

Para análise do material empírico fornecido pela realização das entrevistas foram aplicados os procedimentos de análise de conteúdo, conforme proposto por Bardin (1977). A análise de conteúdo pode ser definida como um método de investigação do teor ou dos significados presentes nas formas interativas de transmissão de informações ou ideias. Operacionalmente, a análise de conteúdo compreende um conjunto de técnicas que, partindo de pressupostos comuns, acaba por favorecer diferentes aspectos presentes nas comunicações. A análise de conteúdo abrange três etapas: pré-análise, exploração do material e análise dos resultados.

Em consonância com Triviños (1987), a pré-análise pode ser definida como o momento de organização do material sobre o qual se realizará a análise. Já a exploração do material é o momento onde se dá o processo de categorização, isto é, estabelecimento de indicadores de análise e também o momento em que se realizam as operações de codificação, estas correspon- dendo ao tratamento do material por meio da sua organização em unidades de registro segundo determinados índices. O índice de codificação aplicado neste artigo objetivou a análise do caráter prioritário ou secundário da intervenção de uma série de dimensões na dinâmica de funcionamento dos programas (critério de prioridade do índice Ordem). A análise dos resultados, por fim, consiste na etapa de interpretação do material sob o respaldo do referencial teórico que ampara a pesquisa e com vistas à contemplação do objetivo do estudo.

\section{O TRABALHO DE CAMPO EM GEOGRAFIA: EM MEIO A RESULTADOS E DISCUSSÕES NECESSÁRIAS}

O trabalho de campo consiste, seguramente, na técnica de coleta de dados mais consagrada e disseminada na Geografia. A proeminência do trabalho de campo nos estudos geográficos remonta às origens da Geografia e sua orientação inicial para pesquisas exploratórias encetadas por viajantes que buscavam recolher dados com o propósito de elaborar relatos descritivos sobre cada porção da superfície terrestre. Possivelmente em razão dessa relação quase intrínseca entre a Geografia e o trabalho de campo, a produção teórica na disciplina pouco explorou os pressupostos do trabalho de campo sob a perspectiva da ciência geográfica, como alertam Chelotti e Pessôa (2009).

Para Hissa e Oliveira (2004) há nessa lacuna na produção geográfica sobre o trabalho de campo resquícios da natureza eminentemente descritiva dos primórdios da Geografia:

Apesar do grande esforço de desenvolvimento epistemológico, a disciplina ainda se percebe, e, assim, repassa a imagem que elabora sobre si mesma, como um saber eminentemente prático, voltado para as coisas concretas e comprometido com o mundo real. A disciplina ainda se percebe, através do exercício dos profissionais e dos discursos produzidos por uma maioria, como a disciplina do concreto e do mundo real: como se o real fosse o visivel, o que assumisse o mundo das formas, das imagens e das superficies. [...] Mas, pouco, ainda, são discutidos os significados do trabalho de 
campo na produção do saber geográfico. [...]. Assim, os trabalhos de campo são percebidos, ainda, como uma visita ao mundo onde se encontra a verdade a ser desvelada - conectada às formas, às superficies (HISSA; OLIVEIRA, 2004, p. 33, grifos dos autores).

Para os autores, a redução da Geografia ao estudo da dimensão material captada pela visão descuida do fato de que as imagens não falam por si mesmas, a forma como são apreendidas depende da perspectiva por meio da qual serão enfocadas. Portanto, ao ver uma imagem o pesquisador enxerga também o reflexo de sua própria visão de mundo em um processo interativo que cerceia a interpretação do visível às construções subjetivas do observador. Por essa razão, adverte Venturi (2011) não existe objetividade pura na condução de um trabalho de campo ou de uma pesquisa científica, porque a visão e também a linguagem por meio da qual uma incursão a campo vai ser abordada são moderadas pelos valores e ideais imanentes às concepções do pesquisador.

$O$ teor de subjetividade envolvido na realização de um trabalho de campo expressa-se pelo fato de que ele não é apenas uma prática exclusivamente científica, como o seria, por exemplo, uma análise laboratorial; o trabalho de campo exige o estabelecimento de uma relação interpessoal de troca que leva à produção de conhecimento. Nesse processo, a coleta de dados e o conhecimento produzido terão também as marcas das contribuições dos sujeitos investigados, os traços da sua subjetividade e da realidade em que vivem.

Por isso, Brandão (2009) entende que convém fugir da tendência a buscar para todos os contextos uma explicação final, que atinja o determinante mais primevo, remontando, por exemplo, à dinâmica assimétrica do capital. Não se trata de negar que grande parte dos processos observados em campo sofram interferência dessa dinâmica, mas sim de não permitir que essa compreensão leve o pesquisador a negligenciar processos que possuem articulações conjunturais, relações subjetivas e simbólicas que também merecem ser analisadas e explicadas.

É para essas análises menos generalistas e mais conectadas com as dinâmicas territorialmente estabelecidas que se buscou - como indicado na introdução - dirigir as linhas de investigação sobre o PAA e o PNAE. Em última instância, essa opção repercute um atualizado entendimento sistêmico, capaz de transitar entre o todo e a parte, sem isolar-se em particularismos insulados ou perder-se em ilações genéricas. Com base nessa concepção, a Figura 1 apresenta as limitações territoriais enfrentadas pelo PAA do RE da UFPel, conforme o critério de prioridade (índice de codificação ordem) indicado por cada grupo entrevistado. As limitações em que as marcações dos eixos se encontram mais próximas do centro do gráfico indicam menor relevância do problema para os grupos inquiridos. Enquanto aquelas em que as marcações dos eixos posicionam-se mais próximas das bordas do gráfico denotam um maior grau de premência ou se constituem em entraves com maior potencial limitador.

Figura 1 - Grau de prioridade com que os grupos entrevistados avaliam as limitações territoriais enfrentadas pelo PAA do RE da UFPel

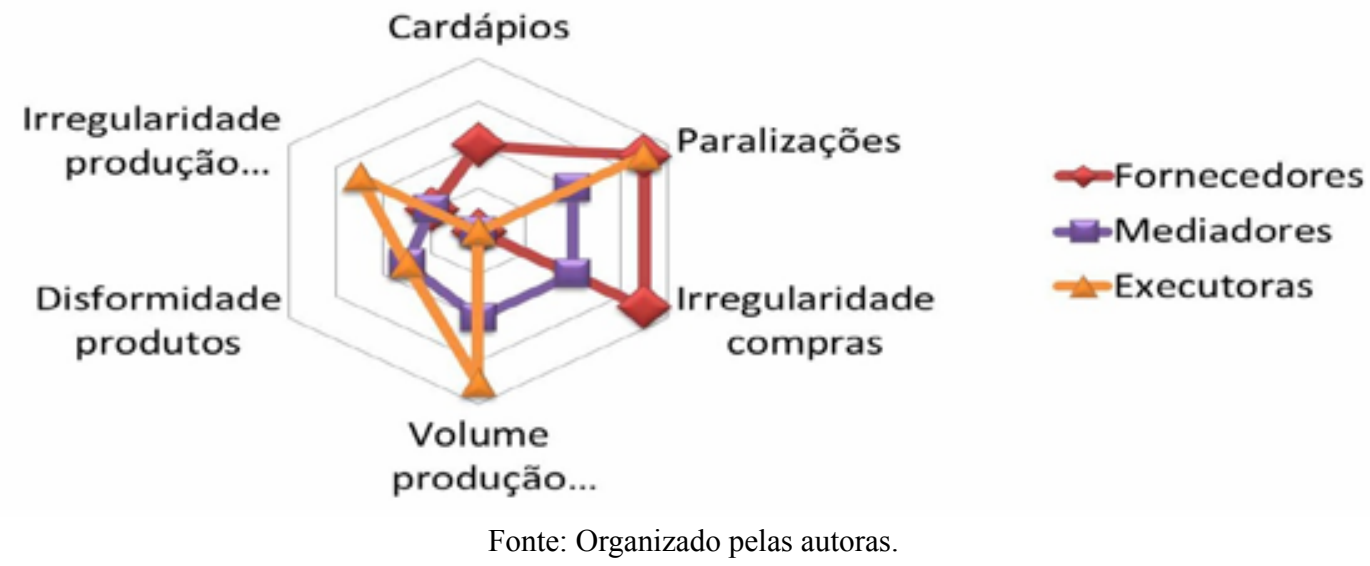


Deve-se destacar que a Figura 1 e, na sequência, as Figuras 2 e 3 expressam igualmente a análise do índice de codificação ordem a partir do critério de prioridade. Para a definição das posições de cada uma das séries de dados que compõem esses gráficos, tomou-se em consideração, fundamentalmente, a ênfase dada pelos entrevistados e não algum critério quantitativo, como o número de menções a determinado fator. Evidentemente, para que um elemento fosse inserido nesses gráficos foi necessário o seu reconhecido por parte significativa dos informantes dos grupos focalizados, o que implica a existência de uma base quantitativa de referências. Esse critério foi considerado, no entanto, exclusivamente para a inserção de um elemento no gráfico, o seu posicionamento na grade, de modo inverso, considera apenas a ênfase dada pelos entrevistados.

Os fornecedores e as executoras entendem que o principal problema do PAA do RE consiste nas greves ou paralizações que afetam a universidade. Nesses momentos, gera-se um impasse sobre o destino da produção, que os fornecedores precisam entregar ao RE, pois não dispõem de outro mercado para o seu escoamento. Enquanto o RE, por sua vez, não encontra nenhum destino possível para os alimentos, sendo, por vezes, obrigado a descartá-los, uma vez que o regimento interno da universidade impede que o RE realize a doação de alimentos. Com o mesmo nível de premência das paralizações, os fornecedores destacam ainda o volume irregular de compras durante os períodos em que as aquisições do RE ocorrem fora da vigência de uma chamada pública do PAA e a insegurança que marca esses períodos, como expressa um fornecedor: "Estão comprando hoje, mas não tem nenhum contrato que garanta a continuidade disso."

As executoras reconhecem que a realização de chamadas públicas permite uma maior margem de organização e planejamento para o agricultor e entendem a necessidade de utilização desses instrumentos. Ao mesmo tempo, destacam que a compra direta dá ao RE maior flexibilidade no gerenciamento do volume de compras ao longo do ano, contribuindo para que se evitem desperdícios. Os fornecedores também destacam como uma limitação importante - ainda que não tão prioritária quanto as duas anteriores - a composição dos cardápios do RE, destacando sua incompatibilidade com as características produtivas da agricultura local e com a sazonalidade dos cultivos.

Assim como os fornecedores, as executoras preferem associar os principais problemas do PAA ao polo oposto, entendendo como empecilho limitador do aumento das compras da agricultura familiar por parte do RE a incapacidade dos fornecedores de oferecer o montante quantitativo de alimentos que o restaurante demanda. De modo geral, a análise da forma como os informantes dimensionam as limitações territoriais dos programas indica que a tendência a associar ao segmento oposto a responsabilidade pelos problemas identificados nos programas - de forma recíproca e mais direcionada entre fornecedores e executoras, e de modo difuso entre fornecedores e executoras na compreensão dos mediadores - permeia o posicionamento dos três grupos entrevistados. É como "self-deception" que Morin (2000) se refere a esse tipo de lógica, ou seja, à propensão humana a eximir-se de responder por suas falhas ou a encontrar subterfúgios que justifiquem esses erros, imputando aos outros a responsabilidade por problemas, erros ou insucessos.

Para o autor, trata-se de uma manifestação de egocentrismo, assim caracterizada:

A self-deception é um jogo rotativo complexo de mentira, sinceridade, convicção, duplicidade, que nos leva a perceber de modo pejorativo as palavras ou os atos alheios, a selecionar o que lhes é desfavorável, eliminar o que lhes é favorável, selecionar as lembranças gratificantes, eliminar ou transformar o desonroso. [...] Mascaram-se as próprias carências e fraquezas, o que nos torna implacáveis com as carências e fraquezas dos outros (MORIN, 2000, p. 96-97, grifo do autor).

A "self-deception" não é uma falha de caráter do ser humano, mas sim o reflexo de uma incompreensão generalizada dos outros e, primeiramente, de si mesmo e da realidade que o cerca. Funciona como um mecanismo de autoproteção legitimado por um pensamento cartesiano redutor. Incapaz de conceber a natureza ampla e complexa da realidade e dos seres humanos, esse pensamento contenta-se com seccionamentos sistemáticos, os quais, focalizando as partes 
do real apenas enquanto partes, acabam por distorcer a compreensão humana e difundir a incompreensão do outro.

Para combater a "self-deception", Morin (2000) recomenda o recurso à ética da compreensão, isto é, ao autoexame de posturas individuais e à tentativa de compreensão do outro antes da sua condenação sumária. Não obstante o fato de que a presença da "self-deception" ainda se mostre preponderante na forma coletiva como os grupos de entrevistados enxergam a ação uns dos outros, como apontado aqui e como poderá verificar-se com relação ao PNAE Estadual e Municipal, entende-se que a existência no município de um Grupo de Trabalho que se reúne mensalmente para debater as operações do PNAE Municipal (GT-PNAE) - o GT agrupa representantes das três cooperativas fornecedoras de Pelotas focalizadas pela pesquisa, da EMATER e das secretarias municipais de educação, de finanças e de desenvolvimento rural -, funcionando como esfera de diálogo entre diferentes atores, tem contribuído para a difusão da ética da compreensão entre os grupos entrevistados.

O GT-PNAE constitui-se em um espaço de diálogo entre fornecedores e mediadores que favorece a explicitação da posição e das condições de cada grupo, estimulando nos envolvidos o reconhecimento de suas próprias falhas e da conjuntura que leva os demais grupos a incorrerem em equívocos. Trata-se de um processo de formação para a ética coletiva que extrapola o âmbito do PNAE Municipal. Uma vez que, embora não dirigido para o PAA do RE da UFPel, a atuação do GT-PNAE também apresenta reflexos sobre aquele programa e sobre o PNAE Estadual, pois, com exceção das executoras, os demais grupos que compõem esse fórum também estão envolvidos na operacionalização do PAA e do PNAE Estadual.

Com a mesma prioridade da questão das paralizações, as executoras apontam a impossibilidade dos fornecedores de entregar uma produção constante em termos de volume e de gêneros ofertados. Ainda que exista um grande esforço no sentido de adquirir tudo o que o sistema familiar puder oferecer e um entendimento acerca da melhor qualidade dos alimentos oriundos desse segmento, como enfatiza este informante do grupo das executoras "[...] tudo que eles podem produzir a gente compra, tudo. Se eles disserem que vão começar a criar porco, a gente compra, com certeza, a gente sabe que é muito melhor."

A disformidade dos produtos, que leva ao desperdício de alimentos em razão do fato do $\mathrm{RE}$ utilizar equipamento industrial para descascar e cortar os hortifrutigranjeiros servidos aos alunos, é apontada como um problema apenas eventual na atualidade, dado o avanço das cooperativas no sentido de permitir maior uniformidade à sua produção. Quanto aos mediadores, todas as limitações acima analisadas são destacadas como fatores limitantes com graus de prioridade semelhantes, não havendo uma tendência a responsabilizar prioritariamente fornecedores ou executoras, mas compreendendo a necessidade de avanços e ajustes por parte dos dois grupos.

A Figura 2 trata das limitações territoriais do PNAE Estadual em Pelotas. Como é possível visualizar no gráfico, o entendimento dos fornecedores e dos mediadores sobre as limitações prioritárias se mostrou coincidente em praticamente todos os pontos levantados nas entrevistas, com exceção do que diz respeito à capacidade produtiva da agricultura familiar do município. Para os fornecedores, o sistema agrário familiar possui plenas possibilidades de atendimento de demandas consideravelmente maiores do que a que os mercados institucionais do município adquirem atualmente. Ao passo que os mediadores entendem que o segmento não dispõe de capacidade produtiva para atendimento de demandas muito maiores do que as que os mercados institucionais representam no cenário atual. 
Figura 2: Grau de prioridade com que os grupos entrevistados avaliam as limitações territoriais enfrentadas pelo PNAE Estadual em Pelotas

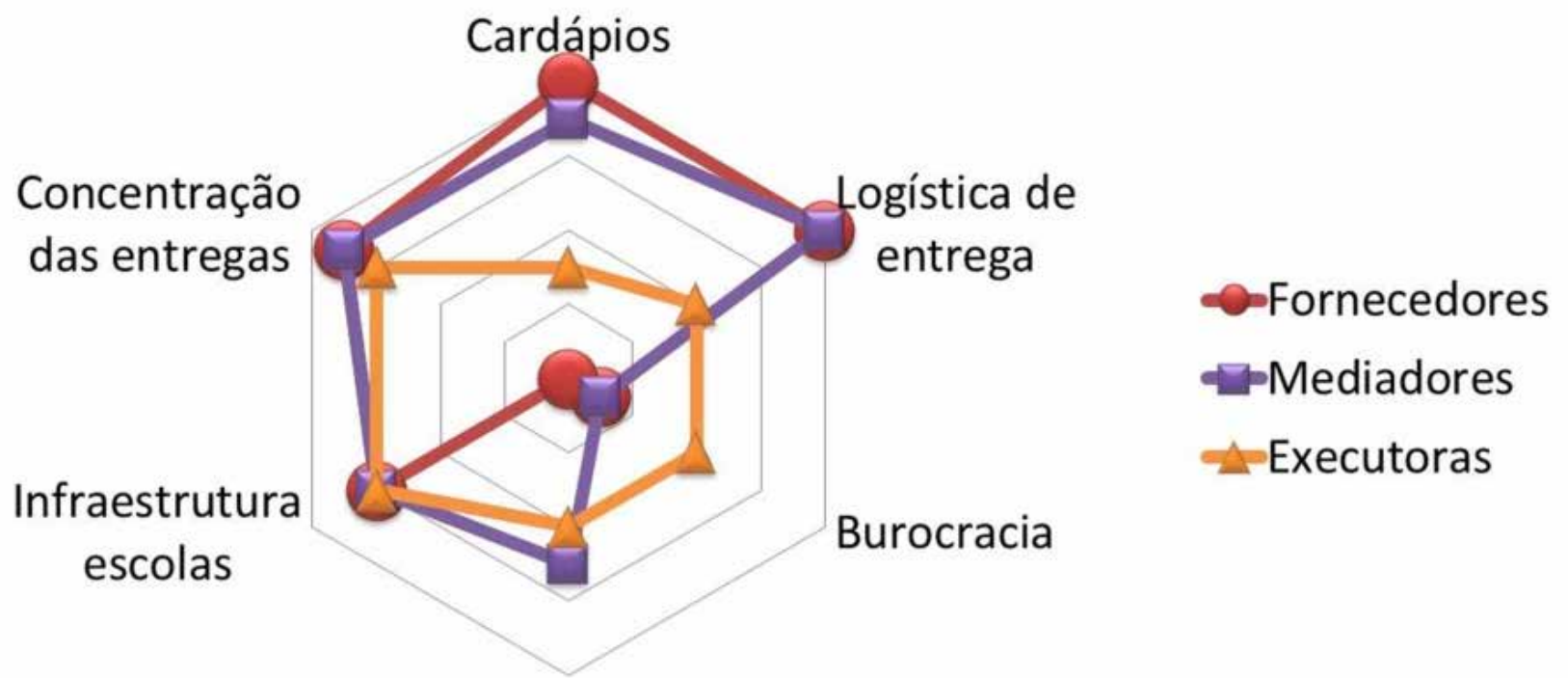

Capacidade

prod. AF

Fonte: Organizado pelas autoras.

Ambos, fornecedores e mediadores, entendem que a dissonância entre os cardápios e as características da produção familiar do município é, a exemplo do caso do PAA, um sério limitador, que, ao lado da logística de entrega do programa na execução estadual, torna esse mercado relativamente inviável para a agricultura familiar. Isso porque o PNAE Estadual possui uma dinâmica escolarizada, as chamadas públicas são feitas individualmente por cada escola em diferentes períodos do ano. Essa logística torna quase inexequível para os fornecedores a realização das entregas, o que poderia ser relativamente amenizado se as escolas possuíssem o mobiliário adequado para o armazenamento dos produtos da agricultura familiar, possibilitando, assim, a realização de entregas em maior volume por parte dos fornecedores. Mas ocorre justamente o contrário, os entraves infraestruturais das escolas atuam como limitador adicional à entrega de maiores volumes de alimentos pelos fornecedores.

Nesta última limitação, incluem-se também as deficiências das escolas no que se refere à disponibilidade de merendeiras para o preparo dos alimentos da agricultura familiar. Alimentos que requerem um maior número de procedimentos antes de serem servidos aos alunos e também demandam maior tempo para o seu preparo em relação aos alimentos industrializados adquiridos por meio de licitação. A resistência das merendeiras aos produtos da agricultura familiar e, principalmente, aos produtos orgânicos é uma limitação frequentemente aludida pelos três grupos entrevistados. Sobre essa questão, as executoras se mostram menos transigentes com a postura das merendeiras, associando sua resistência inclusive a certo grau de displicência no exercício de suas atribuições profissionais. Já os fornecedores e mediadores assumem uma postura mais compreensiva sobre as limitações estruturais que dificultam as atividades dessas profissionais, além de considerarem o desestímulo natural promovido pela desvalorização profissional da categoria.

A concentração das entregas é outra limitação cuja primazia é reforçada com veemência similar entre os três grupos. Tanto no PNAE Estadual quanto no Municipal, a Cooperativa Sul-Rio-Grandense de Laticínios Ltda. (COSULATI) concentra a maior parte do volume de compras da agricultura familiar realizado pelas escolas, como aponta uma entrevistada da entidade executora: "A COSULATI é a única que produz mesmo, o resto [outras cooperativas] é pouquíssimo." 
Isso se deve primeiro ao fato da COSULATI entregar produtos processados com maior valor agregado (leite e derivados e frango). Ao passo que as demais cooperativas entregam essencialmente hortaliças e frutas in natura ou minimamente processados, isto é, hortifrutigranjeiros submetidos "a uma ou mais alterações físicas, como lavagem, descascamento, fatiamento e corte, e em alguns casos a tratamentos químicos, tornando-os prontos para o consumo ou preparo." (EMATER, 2015, p. 7). Segundo, em razão da ampla infraestrutura material da cooperativa para a realização das entregas e também de sua farta disponibilidade de pessoal para gerenciar todo o processo de fornecimento para o PNAE Estadual. O que reduz a carga de trabalho e também de tempo que os diretores de escolas precisam dispensar para os procedimentos de compra de alimentos da agricultura familiar.

A capacidade produtiva da agricultura familiar é novamente indicada como uma limitação com peso considerável pelos mediadores, os quais são apoiados também pelas executoras do PNAE Estadual. Quanto ao último grupo, é curioso que este seja o único a apontar a burocracia como um entrave de proporções não desprezíveis, quando para mediadores e fornecedores essa questão tem potencial limitador praticamente nulo, como indica este fornecedor referindo-os aos processos que cercam as compras das escolas estaduais: "o PNAE Estadual é rápido, é pouco [quantidade de produtos fornecida], mas é rápido." Possivelmente, essa minimização dos impactos da burocracia do PNAE Estadual por parte dos fornecedores e mediadores deva-se à comparação dos prazos e trâmites envolvidos neste programa com aqueles da execução municipal do PNAE.

As limitações territoriais do PNAE Municipal (Figura 3) são mais diversas e o consenso entre os grupos pesquisados sobre a prioridade dessas limitações também é menos coincidente do que verificado no PAA e na modalidade estadual do PNAE. A burocracia é o empecilho mais apontado pelos fornecedores e mediadores, dizendo respeito não apenas ao grande número de expedientes que cercam as compras da agricultura familiar e à lentidão com que esses procedimentos ocorrem. Mas também a uma estrutura organizacional e normativa ainda resistente à realização de compras públicas por outros meios que não por licitação.

Figura 3: Grau de prioridade com que os grupos entrevistados avaliam as limitações territoriais enfrentadas pelo PNAE Municipal em Pelotas

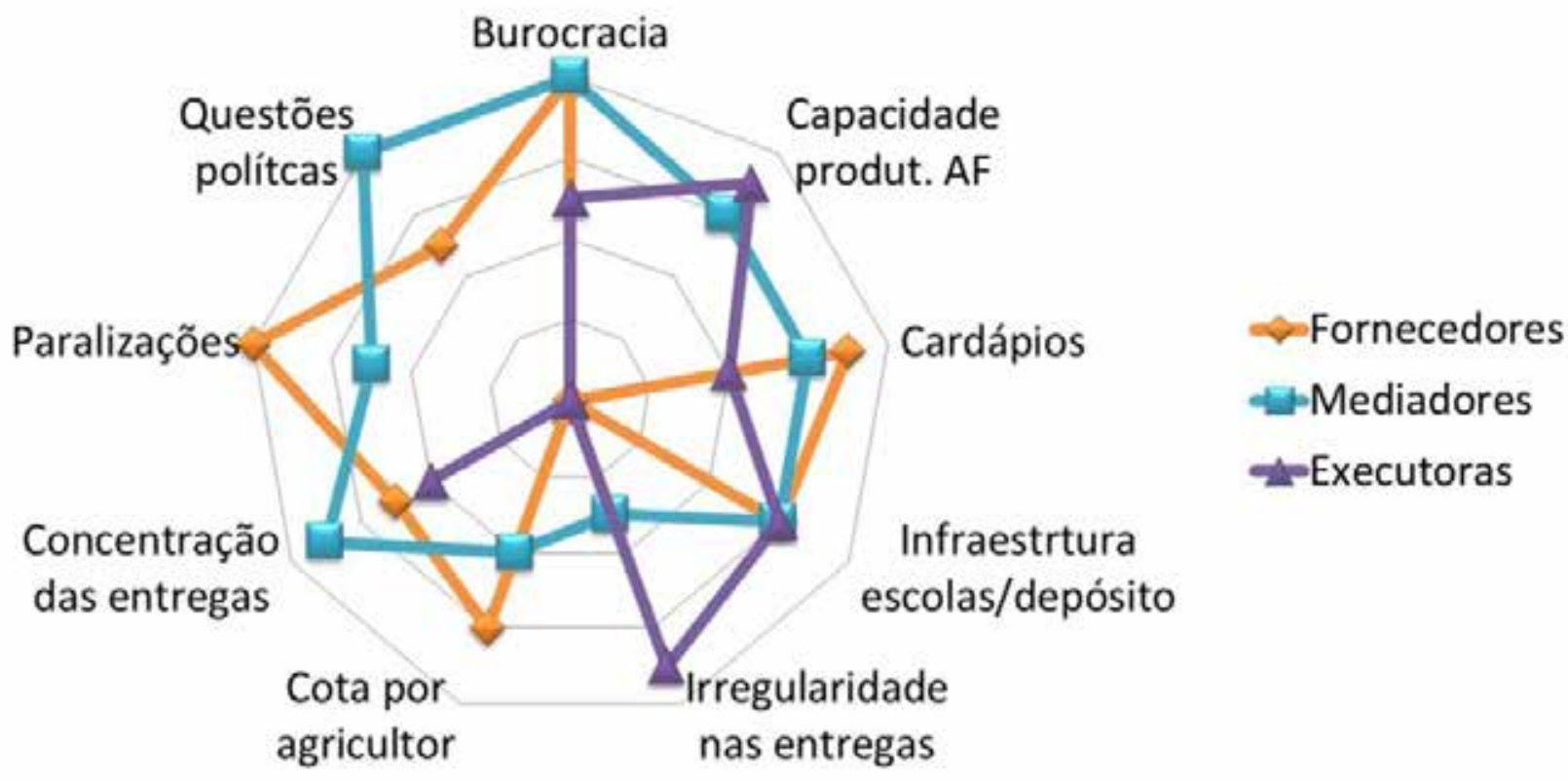

Fonte: Organizado pelas autoras. 
Aqui há, no entanto, uma diferenciação entre o entendimento de fornecedores e mediadores. Enquanto os primeiros reforçam reiteradas vezes que a burocracia do PNAE Municipal é uma característica exclusiva de Pelotas, não ocorrendo nos demais municípios para os quais as cooperativas fornecem, os mediadores entendem que essa limitação permeia de forma indiferenciada as administrações municipais, como afirma este informante:

"[...] tu tens burocratas, o que a gente chama de burocratas, o pessoal do administrativo, do setor de licitações... E tu romperes com esse paradigma, com esse padrão de compra, com essa cultura, que é histórica, de comprar de empresas, tudo muito fácil: licita, ganhou, fornece, pronto. Da onde vem não interessa, veio, está aqui, chegou, beleza. Isso era muito fácil e a gente sabe que em alguns locais tinha, inclusive, corrupção com isso [processo de compra por licitação]. Era um setor [administrativo] em que tu não conseguias mexer muito, por conta dessa facilidade, então até tu começares a mexer nisso leva-se um tempo[...]."

Para os fornecedores, às questões burocráticas soma-se, no PNAE Municipal, a primazia de limitações de ordem política. Ainda que a lei que estabeleça a obrigatoriedade de uma compra mínima da agricultura familiar tenha sido sancionada em 2009, o município de Pelotas apenas começa, efetivamente, a buscar cumprir esse dispositivo legal em 2013, primeiro ano de gestão do atual governo municipal. De acordo com dados da Unidade de Cooperativismo de Pelotas da EMATER, no ano 2012 apenas 5\% do valor repassado via FNDE foi empregue em compras da agricultura familiar, já em 2013 esse percentual atinge a marca de $18,87 \%$, passando a $43,28 \%$ em 2014. Para o ano de 2015 ainda não existem dados fechados, mas os grupos entrevistados estimam que o percentual de aquisições da agricultura familiar tenha sido menor do que o do ano anterior. Isso devido ao fato da primeira chamada pública de 2015 ter acontecido apenas em julho, devido às cooperativas ainda estarem entregando, naquele ano, produtos adquiridos pela executora em 2014.
Como enfatizam Grisa et al. (2015), Pelotas já havia conhecido experiências de compras de alimentação escolar da agricultura familiar ainda em 2001, durante o governo municipal de Fernando Marroni, por meio do Programa de Segurança Alimentar Alimentando a Cidadania. Com a mudança de gestão em 2005, um grupo político opositor ao anterior assume o poder e as compras de produtos do sistema agrário familiar para abastecimento das escolas municipais são interrompidas. Nos anos seguintes esse grupo permanece no governo municipal e mesmo o início do período de vigência da lei em 2009 não altera a postura do governo municipal frente à aquisição de alimentos da agricultura familiar. Para mediadores e fornecedores - de forma mais pronunciada no entendimento destes últimos -, o atual governo tem feito esforços no sentido de ampliar o percentual de compras da agricultura familiar. Mas o fato do PNAE se constituir em um programa do governo federal e a existência de oposição política a esse governo por parte da atual gestão municipal e da anterior operam como desestímulos naturais para o fortalecimento do programa por parte da prefeitura.

As demais limitações apontadas pelos três grupos entrevistados confluem para dinâmicas já apontadas ao analisarem-se as limitações territoriais do PAA e do PNAE Estadual, obedecendo, também, à lógica de "self-deception", aludida por Morin (2000). No entanto, é preciso ressalvar duas exceções, uma quanto às questões de infraestrutura e outra no que se refere ao limite de venda por agricultor para o PNAE. As limitações de estrutura física e de disponibilidade de pessoal para o preparo dos alimentos nas escolas municipais são muito próximas das dificuldades enfrentadas pelas instituições estaduais, a diferença decorre apenas da forma centralizada como a alimentação escolar é gerida no PNAE Municipal. As chamadas públicas no município são feitas de forma unificada pela Secretaria Municipal de Educação e as entregas por parte das cooperativas ocorrem segundo calendário previamente estipulado em um depósito municipal, de onde a prefeitura se encarrega de realizar a distribuição para as escolas. Essa dinâmica favorece a logística de entrega dos produtos pelos fornecedores, mas também comporta problemas estruturais (dimensões limitadas do prédio, insuficiência no número de câmaras frias) sobre as quais os três grupos se mostram de acordo. 
A segunda ressalva, o limite de vendas por agricultor para o PNAE, é uma limitação apontada por mediadores e fornecedores - conquanto apresente diferentes graus de prioridade para cada grupo, conforme indicado na Figura 3. É necessário destacar que a posição dos mediadores sobre a necessidade de aumento do limite de vendas por agricultor não é necessariamente conflitante com a posição desse grupo sobre as limitações na capacidade produtiva das cooperativas. Já que o entendimento dos mediadores sobre a exiguidade do valor-limite estipulado considera fundamentalmente o valor final apropriado pelo agricultor. Para explicar essa linha de entendimento é preciso esclarecer que atualmente o limite de vendas por agricultor familiar para o programa é de $20 \mathrm{mil}$ reais por ano. Desse valor ainda são descontados os custos com logística e processamento dos produtos por parte das cooperativas, uma vez que o PNAE não dispõe de verba administrativa para que as cooperativas cubram os gastos com os esses procedimentos.

Em razão dessa dinâmica operacional do programa, fornecedores e mediadores defendem uma regionalização dos limites de venda para o PNAE que considere as particularidades de cada região. Entende-se que a adoção de limites de comercialização regionais, como proposto pelos próprios entrevistados, pode contribuir sobremaneira para que as diferentes porções do território nacional sejam contempladas conforme suas próprias demandas. Tal mecanismo não atentaria contra a unidade do programa, apenas permitia a sua adaptação aos diferentes contextos territoriais. Da mesma forma, a existência de uma verba administrativa que permitisse às cooperativas cobrir os custos operacionais dos programas poderia ampliar os rendimentos apropriados pelos agricultores e contribuir para o fortalecimento econômico do sistema agrário familiar do município.

Deve-se ressaltar que contemplar as especificidades dos diferentes contextos territoriais a partir da definição de limites de comercialização condizentes com o potencial produtivo de cada sistema agrário não implica, necessariamente, em um reforço das heteronomias que pautam a diversidade de matizes socioeconômicos e culturais com que se apresentam as agriculturas familiares brasileiras. De modo inverso, se determinados sistemas agrários devem ser privilegiados pelas políticas públicas em razão de sua maior fragilidade, outros sistemas, já mais estruturados, podem prescindir de uma intervenção estatal mais ostensiva, demandando, em seu lugar, instrumentos que possibilitem a sua consolidação no contexto socioprodutivo. Dito de outro modo, priorizar os contextos territoriais mais fragilizados não exige que se contenha ou negligencie as possibilidades de crescimento de territórios que já apresentem níveis mais elevados de estabilidade produtiva.

\section{CONCLUSÃO}

A partir da exposição das limitações territoriais do PAA e PNAE em Pelotas foi possível demonstrar a manifestação empírica da definição híbrida de território adotada. Através da análise dos gráficos pode-se explicitar como uma trama de fatores políticos, econômicos e sociais; de ordem material, simbólica, ou culturalmente instituída, atuam no condicionamento das relações entabuladas no território. Ao mesmo tempo, tencionou-se exemplificar a posição anteriormente advogada de que buscar em todas as situações algum tipo de explicação primeira e generalista pode implicar em relegar a grande versatilidade de que é dotado o trabalho de campo. Buscou-se, também, não incorrer no erro de segmentar e compartimentar a realidade, de modo a construir um estudo capaz de encadear o sistema analisado com escalas mais amplas e com a lógica global de funcionamento da sociedade.

Optar pela abordagem sistêmica e pelo conceito de sistema agrário como método e conceito capazes de transitar entre parte e todo, sem perder-se nos compartimentos daquela ou dissolver-se na generalidade deste foi fundamental para identificar a linha diretriz das análises dos grupos entrevistados acerca das limitações territoriais dos programas. Na sistemática dos três grupos de informantes pesquisados de associar majoritariamente as limitações territoriais dos programas à atuação dos outros dois grupos envolvidos, minimizando os problemas ou dificuldades decorrentes da sua própria ação, foi possível perceber uma dinâmica de autoengano (self-decepcion), em que os grupos tendem a ser condescendentes com sua própria ação e bem mais rigorosos ao examinar a atuação dos demais.

Trata-se de uma decorrência de uma visão de mundo fracionada e limitada, que enxerga apenas as 
partes e, por isso, não pode, de fato, compreender a complexidade da realidade e do contexto que cerca e condiciona a ação de cada indivíduo. Todavia, é preciso contrapesar essa afirmação, reforçando o papel fundamental desempenhado pelo GT-PNAE, ao articular e fazer convergir as demandas particulares em um fórum comum. Uma lógica mais solidária tem surgido a partir desse espaço e sua coexistência com a visão fracionária e pouco compreensiva com que os grupos entrevistados enxergam a ação uns dos outros aponta para a simultaneidade da permanência da visão de mundo cartesiana com a insurgência de um pensamento sistêmico e de todas as possibilidades intercooperativas a este imanentes.

\section{REFERÊNCIAS}

BACHELARD, G. O novo espirito cientifico. São Paulo: Abril Cultural, 1978.

BARDIN, L. Análise de conteúdo. Lisboa: Edições 70, 1977.

BERTALANFFY, L. V. Teoria Geral dos Sistemas. 2. ed. Petrópolis: Ed. Vozes, 1975.

BRANDÃO, C. R. Reflexões sobre como fazer trabalho de campo. Sociedade e Cultura, Goiânia, v. 10, n. 1, pp. 11-27, jan./jun. 2007.

CAPRA, F. O ponto de mutação: a ciência, a sociedade e a cultura emergente. São Paulo: Editora Cultrix, 1982.

CHELOTTI, M. C.; PESSÔA, V. L. S. Pesquisa qualitativa com sujeitos da reforma agrária: reflexões sobre o trabalho de campo. In: RAMIRES, J. C. L.; PESSÔA, V. L. S. (Orgs.). Geografia e pesquisa qualitativa: nas trilhas da investigação. Uberlândia: Assis, 2009. pp. 449-484.

EMATER/RS. Atualização do plano de aprimoramento: Cooperativa dos Produtores Agrícolas de Monte Bonito - COOPAMB. SAF/ATER n. 04/2012 L.7. jun. 2015.

GIL, A. C. Métodos e técnicas de pesquisa social. São Paulo: Atlas, 1987.
GRISA, C. et al. Política e religião na rede de execução do Programa de Aquisição de Alimentos (PAA) na região de Pelotas/RS. In: CONGRESSO BRASILEIRO DE SOCIOLOGIA, 17, 2015, Porto Alegre. Anais... Porto Alegre: UFRGS, 2015, pp. 1-17.

HISSA, C. E. V.; OLIVEIRA, J. R. de. O trabalho de campo: reflexões sobre a tradição geográfica. Boletim Goiano de Geografia, Goiânia, v. 24, n. 1-2, pp. 3141, jan./dez. 2004. DOI: http://dx.doi.org/10.5216/ bgg.v24i1.4131

KUHN, T. S. A estrutura das revoluções científicas. 5. ed. São Paulo: Perspectiva, 1998.

MAZOYER, M.; ROUDART, L. História das agriculturas no mundo: do neolítico à crise contemporânea. São Paulo: Editora UNESP, 2010.

MORIN, E. O Método I: a natureza da natureza. 2. ed. Portugal: Publicações Europa-América, 1980.

MORIN, E. Os sete saberes necessários à educação do futuro. 2. ed. São Paulo: Cortez, 2000.

NAVEH, Z. Introduction to the Theoretical Foundations of Multifunctional Landscapes and their Application in Transdisciplinary Landscape Ecology. In: BRANDT, J.; TRESS, B.; TRESS, G. (Eds.). Multifunctional Landscapes: interdisciplinary approaches to landscape research and management. Roskilde: Centre for Landscape Research, 2000. pp. 27-43.

SANTOS, M. O retorno do território. Observatorio Social de América Latina. Buenos Aires, ano 6, n. 16, pp. 251-261, jun. 2005.

SILVA NETO, B.; BASSO D. (Orgs.). Sistemas agrários do Rio Grande do Sul: análise e recomendações de políticas. Ijuí: Ed. Unijuí, 2005.

SOUZA, M. J. L. Território da divergência e (da confusão): em torno das imprecisas fronteiras de um conceito fundamental. In: SAQUET, M. A.; SPOSITO, E. S. (Orgs.). Territórios e territorialidades: teorias, processos e conflitos. São Paulo: Expressão Popular, 2009. pp. 57-72. 
TRICHES, R. M.; SCHNEIDER, S. Alimentação escolar e agricultura familiar: reconectando o consumo à produção. Saúde e Sociedade, São Paulo, v. 19, n. 4, pp. 933-945, 2010.

TRIVIÑOS, A. N. S. Pesquisa qualitativa. In: TRIVIÑOS, A. N. S. Introdução à pesquisa em ciências sociais: a pesquisa qualitativa em educação. São Paulo: Atlas, 1987. pp. 116-173.

VENTURI, L. A. B. A técnica e a observação na pesquisa. In: VENTURI, L. A. B. (Org.). Geografia: práticas de campo, laboratório e sala de aula. São Paulo: Sarandi, 2011. pp. 11-28. 